\title{
Fluctuating algal symbiont communities in Acropora palifera (Scleractinia: Acroporidae) from Taiwan
}

\author{
Chaolun Allen Chen ${ }^{1,2, *}$, Jih-Terng Wang ${ }^{3}$, Lee-Shing Fang ${ }^{4}$, Ya-Wen Yang ${ }^{1}$ \\ ${ }^{1}$ Research Center for Biodiversity, Academia Sinica, Nankang, Taipei 115, Taiwan, ROC \\ ${ }^{2}$ Institute of Oceanography, National Taiwan University, Taipei 106, Taiwan, ROC \\ ${ }^{3}$ Department of Food Science and Technology, Tajen Institute of Technology, Yanpu, Pingtung 907, Taiwan, ROC \\ ${ }^{4}$ National Museum of Marine Biology and Aquarium, Hengchun, Pingtung 946, Taiwan, ROC
}

\begin{abstract}
Seasonal dynamics of algal symbiont communities from the reef flat-dwelling coral Acropora palifera was monitored from January 2000 to July 2001 at Tantzei Bay, Kenting National Park, southern Taiwan. Zooxanthellae density and pigment contents monitored throughout the 18 mo sampling period indicated that no significant bleaching occurred in A. palifera. Molecular phylotyping showed that 2 distinct symbionts, Phylotypes C and D, were associated with A. palifera, either individually or simultaneously. Population surveys throughout the bimonthly sampling period demonstrated that the symbiont community within A. palifera was highly dynamic with significant fluctuations; a drop in the Phylotype D percentage occurred in May, which was correlated with a rise in seawater temperature in the late spring/early summer at the sampled reef. Direct tracking of tagged corals provided evidence that seasonal fluctuations in the algal symbiont communities not only involve changes in zooxanthellae densities and pigment contents, but also a reshuffling of different Symbiodinium phylotypes. Our study highlights that stress tolerance among phylotypes urgently needs to be re-evaluated through a better understanding of the physiological traits of symbionts.
\end{abstract}

KEY WORDS: Symbiont community · Phylotype - Stress tolerance $\cdot$ nlsrDNA RFLPs $\cdot$ Symbiont reshuffling

\section{INTRODUCTION}

Coral bleaching, described as the loss of symbiotic dinoflagellates (also known as zooxanthellae) and algal pigments, or both, has been a major global concern for the health of reef corals (Brown 1997a,b, HoeghGuldberg 1999, Fitt et al. 2001, Glynn et al. 2001, Coles \& Brown 2003, Douglas 2003, Hughes et al. 2003). Bleaching has long been regarded to be deleterious in corals; it can lead to reduced fecundity and growth rates, impaired healing after mechanical damage, increased vulnerability to disease infection, and worst of all, mass mortality (reviewed in Brown 1997a,b, Douglas 2003). The mass coral bleaching event of 1998 is considered the most severe on record, and was pri- marily attributed to abnormally high seawater temperatures (reviewed in Hoegh-Guldberg 1999, Hughes et al. 2003). In addition, solar radiation stress also plays an important role in triggering coral bleaching (Brown 1997a,b, Coles \& Brown 2003).

The loss of symbiotic dinoflagellates involves changes in the zooxanthellae density in the tissues of reef corals. It has been shown that the density of zooxanthellae associated with coral tissues is not necessarily constant throughout the year (Stimson 1997, Brown et al. 1999, Fagoonee et al. 1999, Fitt et al. 2000, Warner et al. 2002). A study of Pocillopora damicornis in Hawaii indicated that symbiotic algal density responded to seasonal differences in environmental parameters with a positive correlation between the 
concentration of dissolved $\mathrm{NO}_{3}$ and algal density, and a negative correlation between algal density and solar radiation (Stimson 1997). A 5 yr monitoring study of symbiotic algal densities in the coral Acropora formosa in Mauritius showed a correlation between density and nitrate concentrations (Fagoonee et al. 1999). Fitt et al. (2000), who studied 5 species of reef-building corals at 3 different depths in the Bahamas for $4 \mathrm{yr}$, indicated that annual fluctuations occurred in tissue mass and symbiotic algal densities. These results show that corals from all depths exhibit bleaching every year, regardless of the color changes visible to human eyes. It was concluded and hypothesized that these patterns are driven by the effects of seasonal changes in light and temperature on algal and animal physiology, and should be applicable to all tropical reef-building corals worldwide (Fitt et al. 2000).

Despite the seasonal dynamics of symbiotic algal densities and their correlations with environmental parameters being well documented in reef-building corals, such changes involving fluctuating algal symbiont diversities within a single colony or population of reef corals are not yet well understood. Symbiotic algae are mainly of the genus Symbiodinium. It is now known that Sybmiodinium is highly diverse and is currently recognized, from molecular evidence, as consisting of 7 major phylogenetic clades (phylotypes) (A to $G$, reviewed in Baker 2003a,b). Among them, Phylotypes A, B, C, D, and F are known to be associated with scleractinian corals (Rowan \& Powers 1991, Rowan \& Knowlton 1995, LaJeunesse 2001, Loh et al. 2001, Santos et al. 2001, Toller et al. 2001a, Baker 2003a,b, Chen et al. 2003, 2004). Recent studies have demonstrated not only the occurrence of multiple phylotypes within coral hosts, but also diverse ecological factors driving the ecological zonation of different phylotypes among coral colonies and even over the surface of individual coral colonies (Rowan \& Knowlton 1995, Rowan et al. 1997, Baker 2001, Toller et al. 2001a,b, Chen et al. 2003, 2004). Symbiodinium diversity is thus thought to be a mechanism by which corals adapt to changing environmental conditions (Buddemeier \& Fautin 1993, Rowan et al. 1997, Baker 2001, 2003a,b).

In this study, the seasonal dynamics of Symbiodinium phylotypes were investigated over an 18 mo period in Acropora palifera on a reef in Kenting National Park, southern Taiwan. A. palifera occurs on a reef flat where disturbances (e.g. wave action, temperature fluctuations, etc.) are high. Our previous study showed that $A$. palifera is associated with 2 distinct Symbiodinium phylotypes, C and D, either individually or simultaneously (Chen et al. 2004). Population-wide surveys during bimonthly samplings and the direct tracking of symbionts within individual coral colonies demonstrated that the symbiont community within A. palifera is highly dynamic, not only involving changes in algal densities but also changes in the compositions of Symbiodinium Phylotypes C and D.

\section{MATERIALS AND METHODS}

Study site and collection of corals. Colonies of Acropora palifera were sampled bimonthly from a reef flat $\left(\sim 1\right.$ to $2 \mathrm{~m}$ in depth) at Tantzei Bay $\left(121^{\circ} 28^{\prime} \mathrm{E}\right.$, $\left.22^{\circ} 35^{\prime} \mathrm{N}\right)$, Kenting National Park, southern Taiwan, from January 2000 to July 2001. A. palifera in this area grows into encrusting plate forms, probably due to the high frequency of disturbances, including strong waves, turbidity, and exposure to the air during spring low tides. Seawater temperatures were converted from data logs deposited by Dr. T.-Y. Fan, National Museum of Marine Biology and Aquarium at the Tiaoshi reef, $2 \mathrm{~km}$ north of our sampling site. Temperature was recorded at 60 min intervals. Our previous survey indicated that $A$. palifera in Tantzei Bay is associated with 2 diverse phylotypes of Symbiodinium, either individually or simultaneously (Chen et al. 2005). It was documented that spatial variations may occur within an individual colony when corals host diverse phylotypes (Rowan et al. 1997). In order to examine the spatial variability in Symbiodinium phylotypes within individual colonies of $A$. palifera, 5 colonies were collected in January 2000, and different parts (margin and center) of each colony were subsampled for molecular phylotyping. For the population survey, $>25$ colonies were randomly sampled by scuba diving along a $50 \mathrm{~m}$ transect line laid on the reef flat. In addition, 20 colonies were tagged in March 2000 to ensure subsequent collection from the same colony. A yellow plastic tag was nailed close to each coral colony. This yellow tag helped us to retrieve the same colony by snorkeling. However, 12 tags were lost due to several typhoons which hit the Kenting National Park area during the sampling period. A piece of coral skeleton (about $5 \mathrm{~cm}$ in diameter) was chiseled off from each colony, placed in individual pre-labeled plastic bags, and immediately transported to the laboratory in an insulated cooler.

Monitoring of coral bleaching and determination of densities and chlorophyll species of zooxanthellae. In order to monitor bleaching, seasonal changes in zooxanthellae density and chlorophyll species were examined. Freshly collected pieces of coral were airbrushed with filtered sweater $(0.45 \mu \mathrm{m})$ modified from the method described in Rowan (1991). The samples were airbrushed completely, until they turned white, to ensure the majority of algae were extracted. The resulting homogenized solution was subsampled twice $(15 \mathrm{ml})$ for chlorophyll $a$ and $c_{2}$ determinations. A 
smsall aliquot (ca. $1 \mathrm{ml}$ ) was preserved with $10 \%(\mathrm{w} / \mathrm{v})$ formalin for the zooxanthellae count. Numbers of zooxanthellae were calculated from replicate $(\mathrm{n}=5)$ hemocytometer counts. The other aliquot was preserved in $70 \%$ ethanol for later molecular phylotyping. Chlorophyll samples were centrifuged to collect the algae and were frozen overnight to help break the cells. Acetone was added to the frozen pellet, and the mixture was homogenized in a small glass tissue grinder, then allowed to develop overnight at $-20^{\circ} \mathrm{C}$. Absorbances were read on a spectrophotometer. Chl a and $\mathrm{chl} C_{2}$ contents were calculated using the equations of Jeffery \& Humphrey (1975). The sample of Acropora palifera was nearly flat; thus, surface area was determined by covering the sample with aluminum foil and standardizing the densities, and chl a and chl $c_{2}$. Data from January and March 2000 were not used in the statistical analyses due to a problem of acetone treatment.

Molecular phylotyping. Molecular phylotypes defined by Rowan (1991), Rowan \& Knowlton (1995), and Chen et al. $(2003,2004)$ were used to classify the zooxanthellae associated with Acropora palifera. DNA extraction and phylotyping were modified from methods described by Chen et al. $(2003,2004)$. The brown cell pellets were washed 3 to 5 times with $10 \mathrm{ml}$ aliquots of ZB (ZB: $0.4 \mathrm{M} \mathrm{NaCl}, 10 \mathrm{mM}$ EDTA, $20 \mathrm{mM}$ Tris- $\mathrm{HCl}, \mathrm{pH}$ 7.6, 8 mM DTT, $0.05 \%$ Tween $20,0.05 \%$ Triton 100), and once in DNA isolation buffer (DNAB: $0.4 \mathrm{M} \mathrm{NaCl}, 50 \mathrm{mM}$ EDTA, pH 8.0). After that, cells were resuspended in $0.75 \mathrm{ml}$ of DNAB, containing $1 \%$ $(\mathrm{w} / \mathrm{v})$ sodium dodecyl sulfate (SDS), and heated to $65^{\circ} \mathrm{C}$ for $30 \mathrm{~min}$. Proteinase $\mathrm{K}$ (Promega) was then added to a final concentration of $0.5 \mathrm{mg} \mathrm{ml}^{-1}$, prior to incubation at $50^{\circ} \mathrm{C}$ for at least $6 \mathrm{~h}$. Subsequently, samples were extracted with phenol/chloroform, and DNA was precipitated with absolute ethanol and $0.3 \mathrm{M}$ sodium acetate overnight at $-20^{\circ} \mathrm{C}$. Precipitated DNA was resuspended in $100 \mu \mathrm{l}$ aliquots of water and stored at $-20^{\circ} \mathrm{C}$. Two sets of genetic markers, nuclear smallsubunit ribosomal DNA (nssrDNA) and nuclear largesubunit DNA (nlsrDNA), were used to assay the zooxanthellae phylotypes. nssrDNA was obtained by PCR amplification with a host-excluding primer pair (ss5z: 5'-GCAGTTATAR TTTATTTGAT GGTYRCTGCT AC-3', and ss3z: 5'-AGCACTGCGT CAGTCCGAAT AATTCACCGG-3), and then characterized using the restriction enzymes, Sau3A I and Taq I, which differentiate 4 of the Symbiodinium phylotypes, A, B, C, and D (Baker 2003a). The $5^{\prime}$-end of the nlsrDNA was amplified using a host-excluding primer pair (5S: 5'-GCCGACCCGCTGAATTCAAGCATAT-3', and D23zoox: 5'-TGTGGCAYGT GACGCGCAAGCTAAG-3'). The PCR was performed in a PC-9606 thermal sequencer (Corbett Research), using the following thermal cycles:
1 cycle at $95^{\circ} \mathrm{C}(3 \mathrm{~min}), 50^{\circ} \mathrm{C}(1 \mathrm{~min})$, and $72^{\circ} \mathrm{C}(2 \mathrm{~min})$; 4 cycles at $94^{\circ} \mathrm{C}(30 \mathrm{~s}), 50^{\circ} \mathrm{C}(1 \mathrm{~min})$, and $72^{\circ} \mathrm{C}(2 \mathrm{~min})$; and 25 cycles at $94^{\circ} \mathrm{C}(30 \mathrm{~s}), 57^{\circ} \mathrm{C}(1 \mathrm{~min})$, and $72^{\circ} \mathrm{C}$ (2 min). The amplification reaction was conducted with 50 to $200 \mathrm{ng}$ of a DNA template and MBI Taq polymerase (Fermantas), in a $50 \mu \mathrm{l}$ reaction volume using a buffer supplied with the enzyme under conditions recommended by the manufacturer. The PCR products were electrophoresed in a $1 \%$ agarose (FMC Bioproduct) gel, using $1 \times$ TAE buffer to assess the yield. PCR products were then characterized using the restriction enzyme, Rsa I (Chen et al. 2003, 2004). All enzymes were purchased from MBI (Fermantas).

Statistical analyses. Statistical analyses were performed using Statview 5.1. Non-parametric statistics was adopted since data were not normally distributed. The significance of zooxanthellae densities, chl $a$, and chl $c_{2}$, measured over the duration of the study, were determined by the Kruskal-Wallis test. The significance of seasonal fluctuations and pairwise comparisons of phylotypic compositions in the bimonthly population survey were examined using Friedman's test and a chi-square test, respectively.

\section{RESULTS}

No visual bleaching occurred in Acropora palifera during the sampling period. This was supported by the zooxanthellae densities and pigment contents (Fig. 1), which were within a range of values for an unbleached status of zooxanthellae densities (Brown 1997a, b, Fagoonee et al. 1999, Fitt et al. 2000). Algal densities fluctuated significantly over time $\left(F_{7,267}=7.05, \mathrm{p}<\right.$ 0.001, Fig. 1A). Similar patterns were also observed for the pigments; $c h l a\left(F_{7,267}=10.89, \mathrm{p}<0.001\right)$ and chl $c_{2}$ $\left(F_{7,267}=10.6, \mathrm{p}<0.001\right)$ (Fig. 1B).

Molecular phylotyping using PCR and restriction fragment length polymorphisms (RFLPs) of nssrDNA and nlsrDNA clearly indicated that Symbiodinium Phylotypes C and D were the 2 phylotypes associated with Acropora palifera. Among the 328 isolates, 3 types of associations, Phylotype C, Phylotype D, and a mixture of Phylotypes $C$ and $D$, were found in the population of A. palifera off the reef flat in Kenting National Park, southern Taiwan (Figs. 2 \& 3). Molecular cloning and DNA sequencing confirmed the coexistence of the 2 phylotypes in A. palifera (Chen et al. 2004).

Five colonies were collected to examine the spatial variability in Symbiodinium phylotypes within an individual colony. Two colonies contained only Phylotype $\mathrm{C}$, and 1 colony contained only Phylotype D. The other 2 colonies, which contained both Phylotypes C and D, showed a uniform distribution throughout the colony. Acropora palifera associated solely with Phylotype D, 


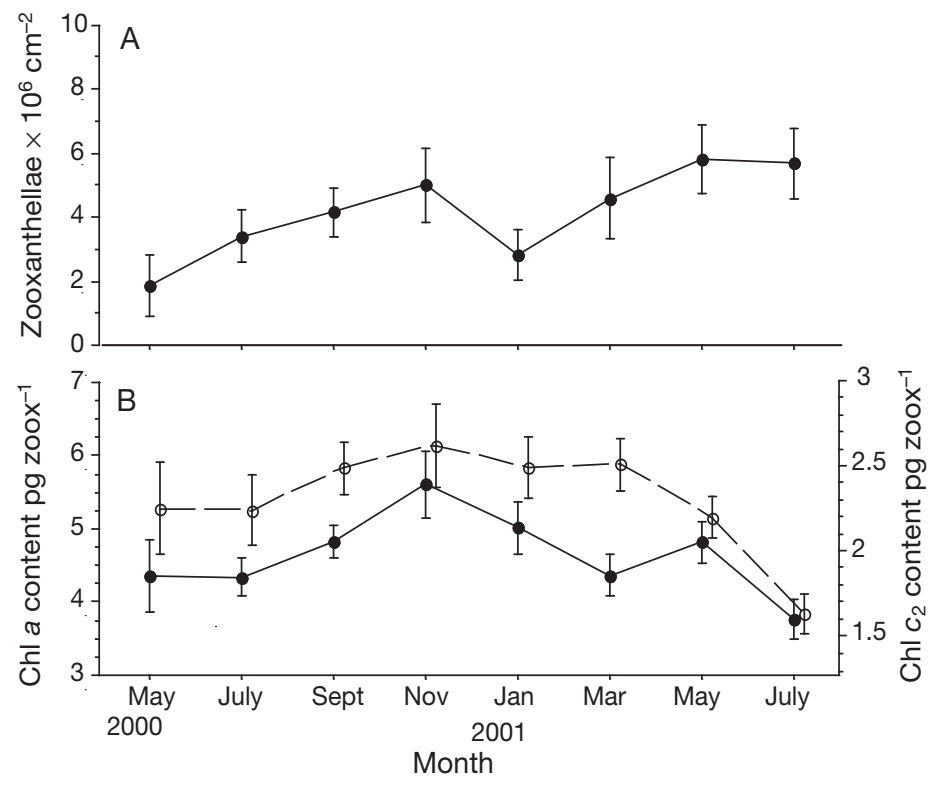

Fig. 1 Acropora palifera. (A) Density of zooxanthellae, (B) chl $a(\bullet)$, and chl $C_{2}(O)$ in relation to time of year. Data are expressed as the mean $\pm 95 \%$ confidence interval

and this was the major type of symbiosis found in the bimonthly sampling, ranging from 33.3\% in May 2001 to $80.65 \%$ in July 2000. The association with only Phylotype C peaked in both May 2000 (40\%) and 2001 (36.67\%). Low frequencies of colonies with a mixture of Phylotypes C and D were observed throughout the study period, ranging from $3.23 \%$ in July 2000 to 23.68\% in March 2001 (Fig. 2). The seasonal fluctuation in Symbiodinium compositions was significant over time (Friedman's test, $\chi^{2}=12.95, \mathrm{p}<0.05$ ) and variable in pairwise comparisons (Table 1). The highest significant difference was found for the comparison between May of both 2000 and 2001, and other months $\left(\chi^{2}\right.$-test, $\left.\mathrm{p}<0.001\right)$. This was reflected in the composition of Phylotype D, which dropped significantly in May of both 2000 and 2001 (Fig. 3). Tracking of tagged colonies provided the first evidence that the compositions of the symbiont community can completely shift from a single phylotype to a mixture of phylotypes and vice versa (Fig. 4). This fluctuation in the symbiont community differed among individual hosts; i.e. in some colonies, symbiont phylotypes fluctuated greatly among months. For example, Colony no. 2 hosted Phylotype C in March 2000, then started to incorporate Phylotype D in July 2000, and shifted only to D in September 2000. Following these shifts, colony no 2. returned to solely hosting Phylotype $\mathrm{C}$ in November 2000. In 2001, the symbiont community in this colony also fluctuated dramatically. In contrast, some colonies retained the same phylotype throughout the entire sampling period (Colony no. 6, Fig. 4).

\section{DISCUSSION}

The data sets collected in this study indicated that zooxanthellae densities and pigment contents of Acropora palifera varied temporally. There is a consensus that zooxanthellae density in reef-building corals averages $1 \times 10^{6}$ cells $\mathrm{cm}^{-2}$, but considerable variations have been reported (Brown 1997a,b, Stimson 1997 , Brown et al. 1999, Fagoonee et al. 1999, Hoegh-Guldberg 1999, Fitt et al. 2000). In contrast, bleached corals have densities of less than $0.5 \times 10^{6}$ cells $\mathrm{cm}^{-2}$ (Fagoonee et al. 1999, Fitt et al. 2000). The zooxanthellae densities in A. palifera were within this range and showed no visual signs of bleaching during the sampling period. No visible signs of coral bleaching were observed in other scleractinian corals in the same area during the sampling period. It is well-documented that algal density fluctuations are directly influenced by changing solar radiation levels and seawater temperatures (Brown et al. 1999, Fitt et al. 2000). Brown et al. (1999) studied 4 Indo-Pacific massive corals and showed that algal densities had a weak correlation to solar radiation, which declined to minimum values at the time of year when sea surface temperatures reached the annual maximum. A similar temperature effect was also observed in the $5 \mathrm{yr}$ monitoring of 5 Caribbean corals from 2 depth zones, in which the lowest values of algal densities and pigment contents usually occurred during the late summer-fall period (Fitt et al. 2000). Although the algal densities and pigment contents of $A$. palifera were variable among the bimonthly samplings, they did not fit the annual pattern of densities being low during the summer-fall and high in the winter-spring period. This observation might be limited due to a short sampling period (1.5 vs. $\sim 4$ to $5 \mathrm{yr}$ ) in which seasonal patterns do not readily appear.

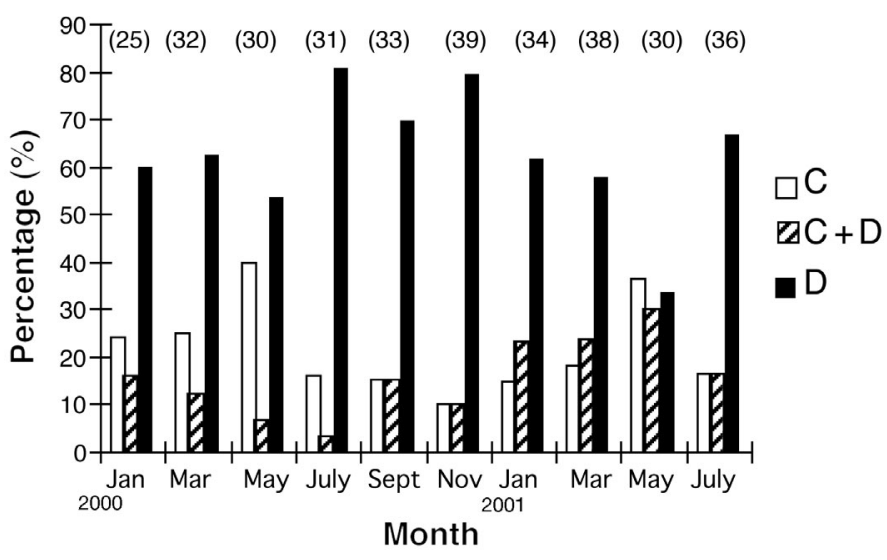

Fig. 2 Acropora palifera. Composition of Symbiodinium phylotypes in relation to time of year. Sample size for each time of year is indicated in parentheses above the bars 
Table 1. Pairwise $\chi^{2}$-test of monthly variation of Symbiodinium phylotype composition based on Fig. 1. ns: not significant; ${ }^{*} \mathrm{p}<$ $0.05 ;{ }^{* *} 0.05<\mathrm{p}<0.001 ;{ }^{* * *} \mathrm{p}<0.001$

\begin{tabular}{|lccccccccc|}
\hline & Jan 00 & Mar 00 & May 00 & Jul 00 & Sep 00 & Nov 00 & Jan 01 & Mar 01 & May 01 \\
\hline Jan 00 & & & & & & & & & \\
Mar 00 & $0.62^{\text {ns }}$ & & & & & & & & \\
May 00 & $7.96^{*}$ & $5.48^{\text {ns }}$ & & & & & & & \\
Jul 00 & $13.62^{* *}$ & $9.90^{* *}$ & $17.74^{* * *}$ & & & & & & \\
Sep 00 & $2.8^{\text {ns }}$ & $3.31^{\text {ns }}$ & $16.62^{* * *}$ & $8.83^{*}$ & & & & & \\
Nov 00 & $9.74^{*}$ & $8.66^{*}$ & $23.65^{* * *}$ & $5.17^{\text {ns }}$ & $2.54^{\text {ns }}$ & & & & \\
Jan 01 & $3.71^{\text {ns }}$ & $6.48^{*}$ & $21.38^{* * *}$ & $18.89^{* * *}$ & $2.58^{\text {ns }}$ & $8.80^{* *}$ & & & \\
Mar 01 & $2.49^{\text {ns }}$ & $5.27^{\text {ns }}$ & $17.89^{* * *}$ & $20.26^{* * *}$ & $3.48^{\text {ns }}$ & $11.26^{* *}$ & $0.40^{\text {ns }}$ & & \\
May 01 & $14.87^{* * *}$ & $18.89^{* * *}$ & $19.07^{* * *}$ & $50.62^{* * *}$ & $27.60^{* * *}$ & $44.40^{* * *}$ & $18.82^{* * *}$ & $14.10^{* * *}$ & \\
Jul 01 & $1.61^{\text {ns }}$ & $2.56^{\text {ns }}$ & $15.08^{* * *}$ & $11.15^{*}$ & $0.31^{\text {ns }}$ & $4.60^{\text {ns }}$ & $1.51^{\text {ns }}$ & $1.87^{7 s}$ & $22.56^{* * * *}$ \\
\hline
\end{tabular}

The seasonal dynamics of algal densities reported in previous studies and our own observations indicate that there is a natural annual pattern of changes in algal-coral symbioses. Our study presents the first evidence that the symbiont community within coral colonies is dynamic, not only as revealed by fluctuating zooxanthellae densities and other parameters but also involving changes in Symbiodinium phylotypes. Symbiotic community change with no visible signs of coral bleaching has been postulated (reviewed in Baker 2003a). This change may involve 2 levels of shifting in host corals: (1) between phylotypes and (2) among different variants within a phylotype. Five distinct phylotypes (A, B, C, D, and F) have been identified as being associated with reef-building corals in the Caribbean, the Indian Ocean, and the Pacific Ocean using conserved nuclear ribosomal-coding genes, nssrDNA, and nlsrDNA (reviewed in Baker 2003a). Multiple phylotypes of Symbiodinium within single individuals and/ or colonies have also been documented in a number of reef-building corals. However, most studies focused on single-time (snapshot) sampling for bathymetric distribution, biogeography, and depth-related patterns of zonation (reviewed in Baker 2003a); therefore, longterm changes in symbiont communities have never been detected. Our results suggest that snapshot sampling might underestimate symbiont diversity, especial for those coral hosts harboring more than 1 phylotype of Symbiodinium. In addition, symbiotic community changes may involve a shifting of different symbionts within phylotypes. For example, several tropical Pacific scleractinians exhibit patterns of depth zonation with 2 variants of Phylotype $C$ using a rapidly evolving region of the ribosomal gene, the internal transcribed spacer (ITS) (LaJeunesse et al. 2002). Whether these 2 variants of Phylotype $\mathrm{C}$ also involve temporal variation within a single coral colony as seen at the phylotypic level is worthy of further investigation.

Several ecological surveys and experiments have implied that there are stress-tolerant differences (to tem- perature, irradiation, etc.) among Symbiodinium phylotypes (Rowan \& Knowlton 1995, Rowan et al. 1997, Baker 2001 2003a,b, 2004, Loh et al. 2001, RodriguezLanetty et al. 2001, Toller et al. 2001a,b, Savage et al. 2002, Chen et al. 2003, 2004, Knowlton \& Rohwer 2003, Rowan 2004). For example, Phylotype D was first recognized as an opportunistic symbiont that plays an important role in recently bleached corals in the process of recovering their steady-state symbiont communities, or corals occurring in stressed and marginal habitats (Rowan et al. 1997, Baker 2001, 2003a,b, Glynn et al. 2001, Toller et al. 2001a,b, Chen et al. 2003, 2004, Fabricius et al. 2004, Little et al. 2004). Phylotype D, on the contrary, is the dominant Symbiodinium (>60\%) as-

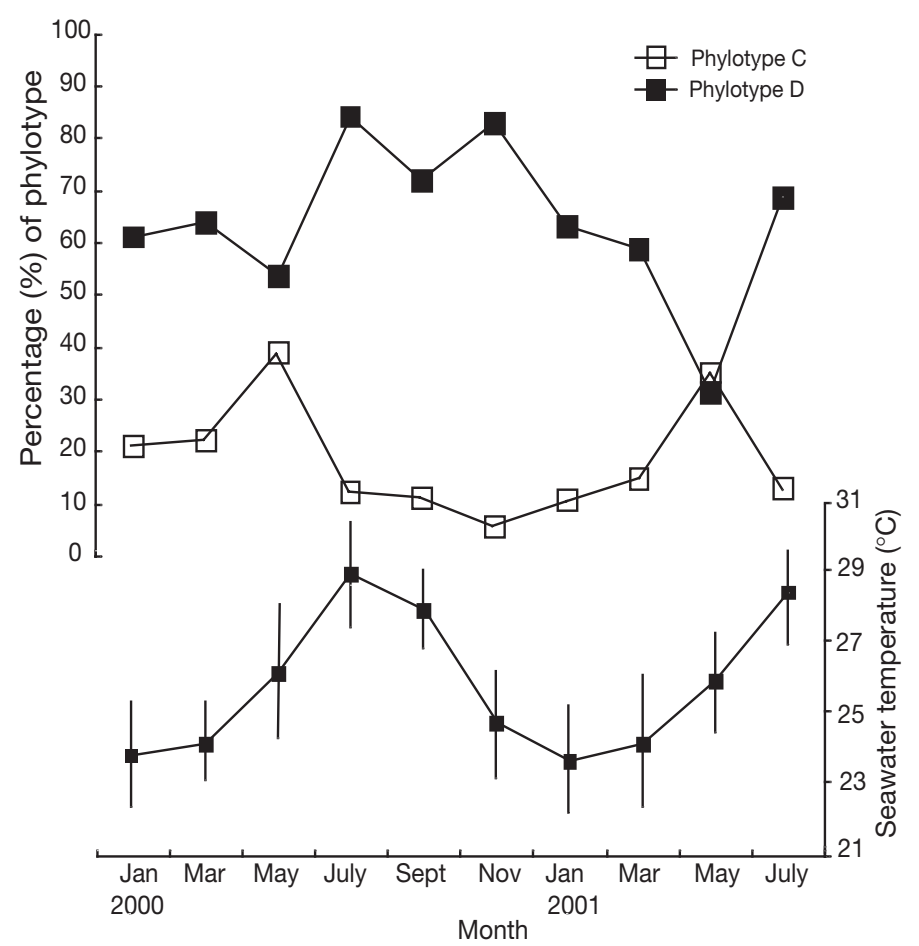

Fig. 3 Acropora palifera. Percentage of Phylotypes C and D and seawater temperature in relation to time of year 


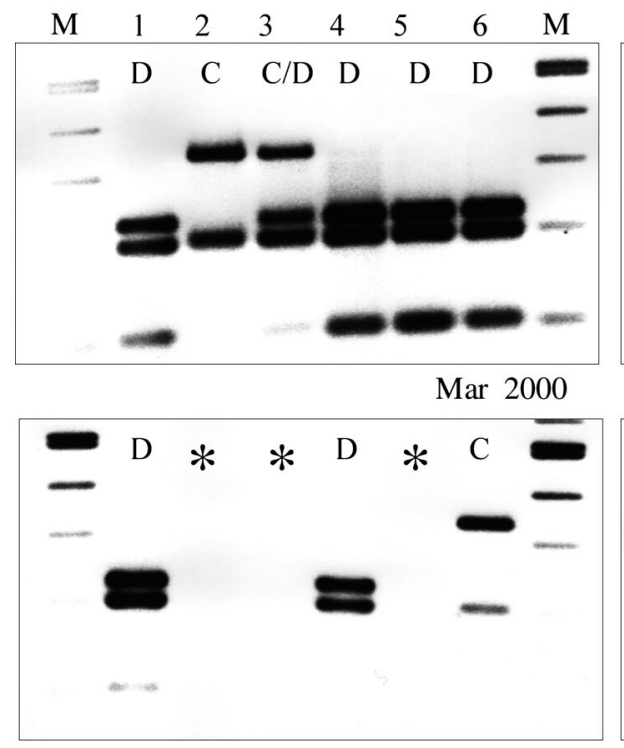

May 2000

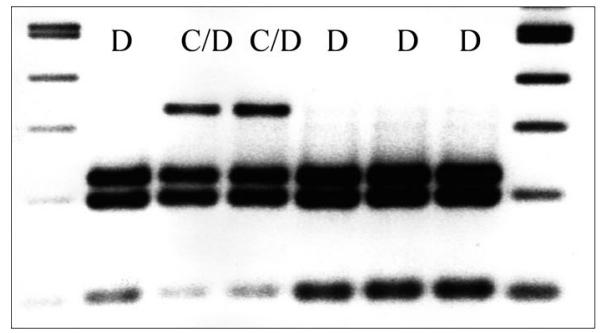

July 2000

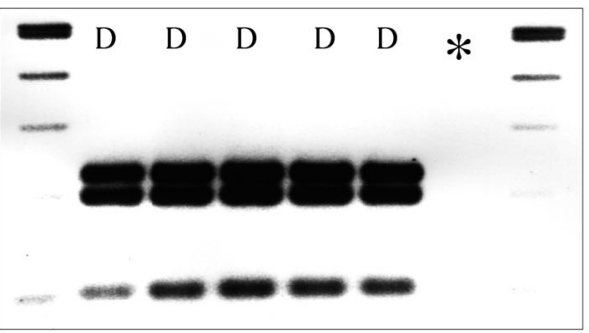

Sept 2000

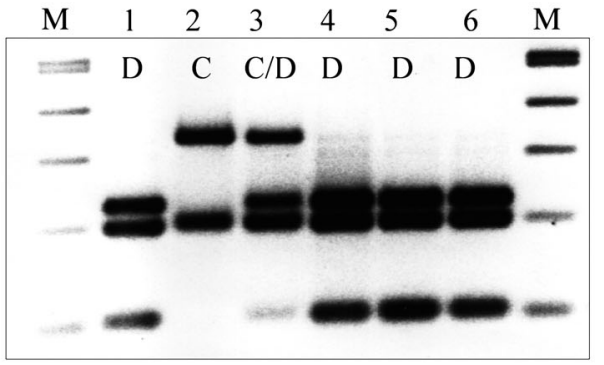

Nov 2000

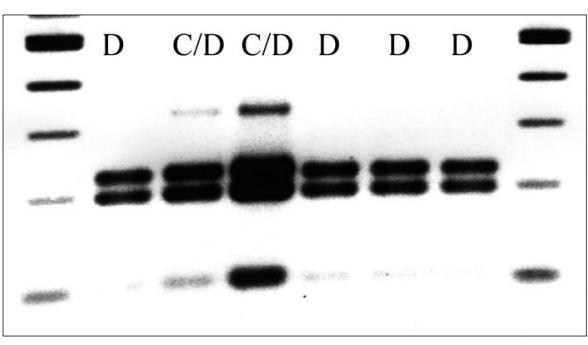

Jan 2001

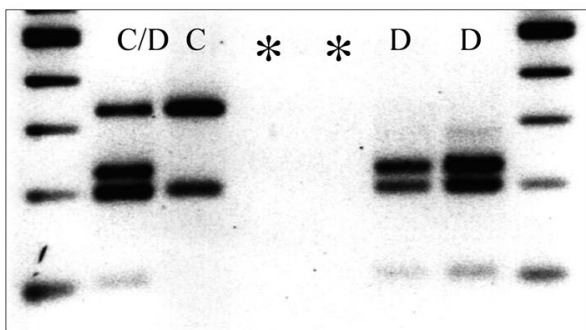

Mar 2001

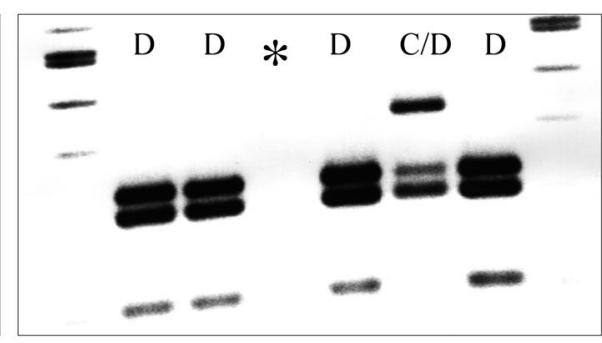

May 2001
Fig. 4. Acropora palifera. RFLP phylotyping of zooxanthellae freshly isolated from several examples of tagged corals throughout the sampling period. PCR products of nuclear large-subunit ribosomal DNA (nlsrDNA) were digested with Rsa I. Lanes at both ends of the gels labeled with $M$ are DNA fragment size standards of a $100 \mathrm{bp}$ DNA ladder. Each lane (1 to 6) on the gel represents the tagged colony subsampled in that month. For example, Colony no. 1 hosts Phylotype D from March 2000 to January 2001, but hosts Phylotypes C and D in March 2001, and then changes back to Phylotype D in May 2001. *PCR amplifications were unsuccessful due to the poor quality of the DNA extraction sociated with Acropora palifera in the shallow water of this reef flat where environmental disturbances are high. Even with the shuffling symbiont communities observed in individual colonies, from Phylotype D to C and C/D or vice versa, our data imply that instead of being an opportunistic symbiont, Phylotype D shows a certain fidelity in its relationship with A. palifera. This view of the physiological potential of Phylotype D was also suggested by the stable association of Phylotype D with the low temperature-tolerant coral Oulastrea crispata in subtropical nonreefal coral communities (Chen et al. 2003). Further surveys of symbiont diversity in O. crispata from temperate Japan to the tropical Gulf of Thailand showed that Phylotype D was as- sociated with this widely distributed coral across the West Pacific (Lein et al. unpubl. data). In addition, Phylotype D was also found in stable associations mixed with Phylotype C in Euphyllia spp. at the reef edge of 2 different coral communities in the Taiwan Strait (Chen et al. 2004). Taken together, although having a higher potential for stress tolerance, Phylotype D may represent the 'best-performing' Symbiodinium for corals living in frequently disturbed environments. Nevertheless, this scenario should be corroborated by studying more coral species co-occurring in the same environment before a firm conclusion can be stated.

Recent studies have taken the further step of suggesting that Phylotype D is a heat-tolerant Symbiodi- 
nium (Glynn et al. 2001, Baker 2003a,b, 2004, Ulstrup \& van Oppen 2003, Fabricius et al. 2004, Little et al. 2004, Rowan 2004). Glynn et al. (2001) showed that Far-Eastern Pacific corals hosting Phylotype D symbionts had suffered less from the 1998 coral bleaching event than those coral associated with other symbiont phylotypes. Acropora millepora was associated with Phylotype D in the warmer inshore reef, and with Phylotype $\mathrm{C}$ in the mid-shelf reefs of the Great Barrier Reef (van Oppen et al. 2001). Baker (2004) found a much higher proportion of Phylotype D in corals that had survived the severe bleaching in the Arabian Gulf than in coral from the Red Sea; the former has greater temperature fluctuations and higher salinities. Fabricius et al. (2004) showed that corals associated with Phylotype D did not suffer coral mortality during the 1998 coralbleaching event in the Palauan reefs. Thermal experiments showed that Pocillopora verrucosa hosting Phylotype D increased photoprotection after exposure to high temperatures, indicating that Phylotype D is a high-temperature specialist (Rowan 2004). The symbiont communities in $A$. palifera fluctuated greatly with Phylotype D, significantly dropping in late spring/early summer when seawater temperatures rose sharply (Fig. 3). Two scenarios for examining the heat-tolerance of Phylotype D could explain these fluctuations of symbiont communities. First, an increase of Phylotype D was observed in summer (July), which corresponded to the highest water temperature in the area. The proportion of Phylotype D remained steady (unchanged) through the whole autumn and early winter, with a significant drop in May of both years. The opposite was true for the distribution of the symbiont from Clade $\mathrm{C}$, which decreased in summer and was stable in winter (Fig. 3). This suggests that either Clade C symbionts are heat-sensitive or Clade D symbionts are heat-tolerant or both. In contrast, A. palifera occurs in the reef flat off Tantzei Bay where corals experience wide-ranging temperature fluctuations daily and monthly. If Phylotype D is specifically heattolerant, it would be reasonable to predict that not only would Phylotype D be the major Symbiodinium, but that it should also be maintained in a stable association with A. palifera living in the shallow reef flat that is constantly exposed to high temperatures during low tides, as seen in Goniastrea aspera inhabiting a similar habitat in Phuket, Thailand (Brown et al. 2000, 2002). G. aspera colonies harbor an apparently uniform Symbiodinium community of Phylotype D. However, the stability of the association was not what we observed for A. palifera in the bimonthly sampling period. The negative correlation indicated that physiological constraints other than heat operated on the fluctuation of Phylotype D in A. palifera. Experiments conducted with 2 Caribbean Montastrea species showed that
Phylotype D is relatively stress-tolerant to changing light levels (Toller et al. 2001b). These results and the discovery of Phylotype D in association with corals inhabiting either shallow water or the reef edge in deep water of both the Caribbean and the Indo-Pacific coral reefs (Toller et al. 2001a, Chen et al. 2004) suggests that the physiological performance of both Phylotype D and the holobionts (the whole-animaldinoflagellate association) cannot be simply explained by heat-tolerance, and other factors (e.g. irradiation, sedimentation etc.) should also simultaneously be considered (Toller et al. 2001a,b).

The significant fluctuation in Symbiodinium composition in Acropora palifera during late spring/early summer might be related to differences in physiological properties between Phylotypes $\mathrm{C}$ and $\mathrm{D}$, and their contribution to the holobionts, although there is little experimental evidence available to justify this hypothesis. Little et al. (2004) monitored the growth of juveniles of 2 Acropora species infected with Phylotypes C and $D$, respectively. It was shown that juveniles infected with Phylotype $C$ grew $\sim 2$ to 3 times faster than those infected with Phylotype $\mathrm{D}$, indicating that algal endosymbionts significantly contribute to the physiological attributes of the coral holobiont (Little et al. 2004). Although a PCR-RFLP survey of tagged A. palifera clearly distinguished Phylotypes $\mathrm{C}$ and $\mathrm{D}$, and their mixture in agarose gels, the PCR technique may fail to detect the existence of a phylotype when its relative density is extremely low. Nevertheless, shuffling the symbiont communities from Phylotype D-dominant to Phylotype C-dominant in A. palifera may still be regarded as a contribution to a better physiological performance of holobionts in the face of seasonal fluctuations of environmental conditions, including temperature and irradiation etc. Determining whether this fluctuation is related to differences of acclimation of physiological performances between Phylotypes $\mathrm{C}$ and $\mathrm{D}$, and their interaction with the coral host requires further confirmation.

In conclusion, our study reveals that the regulation of the symbiotic community within coral hosts is dynamic, and furthermore, may routinely involve changes between different Symbiodinium phylotypes. In addition, significant changes of symbiont compositions during seawater temperature rises in late spring/early summer also highlight that the scenario of stress tolerance among phylotypes urgently needs to be re-evaluated by understanding the physiological traits of symbionts.

Acknowledgements. We would like to thank H.-C. Hsieh for sample collection and laboratory work, and C.-H. Chen for statistical advice. Data on seawater were provided by T.-Y. Fan. This study was made possible by grants from the National Science Council (NSC), Taiwan to C.A.C. and 
L.-S.F., and internal grants from the Institute of Zoology, Academia Sinica and Research Centre for Biodiversity (RCBAS) to C.A.C. J.-T.W. and C.A.C. were supported by NSC postdoctoral fellowships. Many thanks to C.-F. Dai, C.$\mathrm{H}$. Chen, members of the Evolution and Ecology group, RCBAS, and 3 anonymous reviewers for constructive comments. This is the Evolution and Ecology Group, RCBAS contribution no. 31 .

\section{LITERATURE CITED}

Baker AC (2001) Reef corals bleach to survive change. Nature 411:765-766

Baker AC (2003a) Flexibility and specificity in coral-algal symbiosis: diversity, ecology, and biogeography of Symbiodinium. Annu Rev Ecol Syst 34:661-689

Baker AC (2003b) Symbiont diversity on coral reefs and its relationship to bleaching resistance and resilience. In: Rosenberg E, Loya Y (eds) Coral health and disease. Springer, Berlin, p 177-191

Baker AC (2004) Corals' adaptive response to climate change. Nature 403:741

Brown BE (1997a) Coral bleaching: causes and consequences. Coral Reefs 16:S129-138

Brown BE (1997b) Adaptations of reef corals to physical environmental stress. Adv Mar Biol 31:222-299

Brown BE, Dunne RP, Ambarsari I, Le Tissier MDA, Satapoomin U (1999) Seasonal fluctuations in environmental factors and variations in symbiotic algae and chlorophyll pigments in four Indo-Pacific coral species. Mar Ecol Prog Ser 191:53-69

Brown BE, Dunne RP, Goodson MS, Douglas AE (2000) Bleaching patterns in reef corals. Nature 404:142-143

Brown BE, Dunne RP, Goodson MS, Douglas AE (2002) Experience shapes the susceptibility of a reef coral to bleaching. Coral Reefs 21:1191-1226

Buddemeier RW, Fautin DG (1993) Coral bleaching as an adaptive mechanism. BioScience 43:320-326.

Chen CA, Lam KK, Nakano Y, Tsai WS (2003) Stable association of a stress-tolerant zooxanthellae, Symbiodinium clade D, with the low-temperature tolerant coral, Oulastrea crispata, in subtropical nonreefal coral communities. Zool Stud 42:540-550

Chen CA, Wei NV, Tsai WS, Fang LS (2005) Symbiont diversity in the scleractinian corals from tropical reefs and nonreefal communities in Taiwan. Coral Reefs 24:11-22

Coles SL, Brown BE (2003) Coral bleaching-capacity for acclimatization and adaptation. Adv Mar Biol 46:183-223

Douglas AE (2003) Coral bleaching - how and why? Mar Pollut Bull 46:385-392

Fabricius K, Mieog JC, Colin PL, Idip D, van Oppen MJH (2004) Identity and diversity of coral endosymbionts (zooxanthellae) from three Palauan reefs with contrasting bleaching, temperature and shading histories. Mol Ecol 13:2445-2458

Fagoonee I, Wilson HB, Hassell MP, Turner JR (1999) The dynamics of zooxanthellae populations: a long-term study in the field. Science 283:843-845

Fitt WK, McFarland FK, Warner ME, Chilcoat GC (2000) Seasonal patterns of tissue biomass and densities of symbiotic dinoflagellates in reef corals and relation to coral bleaching. Limnol Oceanogr 45:677-685

Fitt WK, Brown BE, Warner ME, Dunne RP (2001) Coral bleaching: interpretation of thermal tolerance limits and thermal thresholds in tropical corals. Coral Reefs 20:51-65 Glynn PW, Mate JL, Baker AC, Calderon MO (2001) Coral bleaching and mortality in Panama and Ecuador during the 1997-1998 El Nino-Southern oscillation event: spatial/temporal patterns and comparisons with the 1982-1983 event. Bull Mar Sci 69:79-109

Hoegh-Guldberg O (1999) Climate change, coral bleaching and the future of the world's coral reefs. Mar Freshw Res 50:839-866

Hughes TP, Baird AH, Bellwood DR, Card M and 13 others (2003) Climate change, human impacts, and the resilience of coral reefs. Science 301:929-933

Jeffery SW, Humphrey GF (1975) New spectrophotometric equations for determining chlorophyll $a, b, c_{1}$ and $c_{1}$ in high plant, algae, and natural phytoplankton. Biochem Physiol Pflanz 167:191-194

Knowlton N, Rohwer F (2003) Multispecies microbial mutualisms on coral reefs: the host as a habitat. Am Nat 162:51-62

LaJeunesse TC (2001) Investigating the biodiversity, ecology, and phylogeny of endosymbiotic dinoflagellates in the genus Symbiodinium using the ITS region: in search of a 'species' level marker. J Phycol 37:660-686

LaJeunesse TC (2002) Diversity and community structure of symbiotic dinoflagellates from Caribbean coral reefs. Mar Biol 141:387-400

Little A, van Oppen MJH, Willis B (2004) Flexibility in algal endosymbioses shapes growth in reef corals. Science 304: 1492-1494

Loh WKW, Loi T, Carter D, Hoegh-Guldberg O (2001) Genetic variability of the symbiotic dinoflagellates from the wide ranging coral species Seriatopora hystrix and Acropora longicyathus in the Indo-West Pacific. Mar Ecol Prog Ser 222:97-107

Rodriguez-Lanetty M, Loh W, Carter D, Hoegh-Guldberg O (2001) Latitudinal variability in symbiont specificity within the widespread scleractinian coral Plesiastrea versipora. Mar Biol 138:1175-1181

Rowan R (1991) Molecular systematics of symbiotic algae. J Phycol 27:661-666

Rowan R (2004) Thermal adaptation in reef coral symbionts. Nature 430:742

Rowan R, Knowlton N (1995) Intraspecific diversity and ecological zonation in coral-algae symbiosis. Proc Natl Acad Sci USA 92:2850-2853

Rowan R, Powers D (1991) A molecular genetic classification of zooxanthellae and the evolution of animal-algae symbioses. Science 251:1348-1351

Rowan R, Knowlton N, Baker AC, Jara J (1997) Landscape ecology of algal symbiont communities explains variation in episodes of coral bleaching. Nature 388:265-269

Santos SR, Taylor DJ, Cofforth MA (2001) Genetic comparisons of freshly isolated versus cultured symbiotic dinoflagellates: implications for extrapolating to the intact symbiosis. J Phycol 37:900-912

Savage AM, Goodson MS, Visram S, Trapido-Rosenthal H, Wiedenmann J, Douglas AE (2002) Molecular diversity of symbiotic algae at the latitudinal margins of their distribution: dinoflagellates of the genus Symbiodinium in corals and sea anemones. Mar Ecol Prog Ser 244: $17-26$

Stimson J (1997) The annual cycle of density of zooxanthellae in the tissues of field and laboratory-held Pocillopora damicornis (Linnaeus). J Exp Mar Biol Ecol 214:35-48

Toller WW, Rowan R, Knowlton N (2001a) Zooxanthellae of the Montastraea annularis species complex: patterns of distribution of four taxa of Symbiodinium of different reefs and across depths. Biol Bull (Woods Hole) 201:348-359

Toller WW, Rowan R, Knowlton N (2001b) Repopulation of 
zooxanthellae in the Caribbean corals Montastraea annularis and $M$. faveolata following experimental and disease-associated bleaching. Biol Bull (Woods Hole) 201: $360-373$

Ulstrup KE, van Oppen MJH (2003) Geographic and habitat partitioning of genetically distinct zooxanthellae (Symbiodinium) in Acropora corals on the Great Barrier Reef. Mol Ecol 12:3477-3484

van Oppen MJH, Palstra F, Piquet AMT, Miller DJ (2001) Pat-

Editorial responsibility: Charles Birkeland (Contributing Editor), Honolulu, Hawaii, USA tern of coral-dinoflagellate associations in Acropora: significance of local availability and physiology of Symbiodinium strains and host-symbiont selectivity. Proc R Soc Lond B 268:1759-1767

Warner ME, Chilcoat GC, McFarland FK, Fitt WK (2002) Seasonal fluctuations in the photosynthetic capacity of photosystem II in symbiotic dinoflagellates in the Caribbean reef-building coral Montastraea. Mar Biol 141: $31-38$

Submitted: March 5, 2004; Accepted: February 18, 2005 Proofs received from author(s): June 1, 2005 